\title{
POISONING IN INDUSTRIAL WORKERS BY THE INSECTICIDE ALDRIN
}

\author{
BY \\ G. KAZANTZIS, * A. I. G. MCLAUGHLIN, and PAMELA F. PRIOR \\ From the Department for Research in Industrial Medicine (M.R.C.) and the \\ Department of Electroencephalography, The London Hospital, London, E.1.
}

(RECEIVED FOR PUBLICATION JULY 1, 1963)

\begin{abstract}
A 23-year-old worker in a formulating plant developed epileptiform convulsions after a short period of heavy exposure to the chlorinated hydrocarbon insecticide aldrin. He was found to have a high concentration in body fat of hexachloro-epoxy-octahydro-dimethanonaphthalene (H.E.O.D.), the principal metabolite of aldrin, and transient electroencephalographic abnormalities. Nine exposed workers from the same factory were examined, and two of these had symptoms suggestive of aldrin poisoning. At a later date one of these two men and one other man developed convulsions associated with abnormalities of the electroencephalogram and high concentrations of H.E.O.D. in body fat. The concentrations of H.E.O.D. in body fat and also in blood and the electroencephalogram were found to be useful in diagnosis, and their value is discussed.
\end{abstract}

Aldrin is a widely-used insecticide which is effective against a large variety of plant and animal pests. It is useful as a soil insecticide, as a seed dressing, and for application to foliage, as well as acting as the basis of many dips, sprays, and dusts for the protection of livestock against parasites. Available as a concentrate for formulation, aldrin is diluted before use to form a range of dusts, wettable powders, and emulsions. In these forms it is available for use in domestic gardens.

Aldrin, dieldrin, and endrin are derivatives of hexahydro-dimethanonaphthalene and, with D.D.T., benzene hexachloride, and toxaphene, are members of the chlorinated hydrocarbon group of insecticides. Aldrin is the common name of a product containing not less than $95 \%$ of the endoexo isomer of $1: 2: 3: 4: 10: 10$-hexachloro-1:4:4a:5: 8:8a-hexahydro-1:4:5:8-dimethanonaphthalene. It is a light brown flaky solid which is soluble in fat and most organic solvents but almost insoluble in water. Absorption into the body can occur through the intact skin, by inhalation, or by ingestion.

Once absorbed, aldrin appears to be rapidly metabolized by epoxidation to the endo-exo isomer of hexachloro-epoxy-octahydro-dimethanonaphthalene (H.E.O.D.) and in this form to be deposited

* Present address: Air Pollution Research Unit (M.R.C.), St. Bartholomew's Hospital Medical College, Charterhouse Square, London, E.C.1. mainly in body fat (Winteringham and Barnes, 1955; Bann, DeCino, Earle, and Sun, 1956). The insecticide dieldrin contains not less than $85 \%$ of the compound H.E.O.D., so that it has often been said that aldrin is metabolized in the body to dieldrin. H.E.O.D. can be readily estimated in body fat, but, in addition, very small quantities have been found in the unsaponifiable fraction of whole blood by the highly sensitive technique of gas-liquid chromatography using an electron capture detector (Robinson, 1963). This method was used for the H.E.O.D. determinations performed in the present investigation.

Poisoning in man is principally manifested by excitation of the central nervous system, producing epileptiform convulsions in the more severe cases. The first reported case of industrial aldrin poisoning in Britain is presented here, together with the results of the examination of nine other workers engaged on the formulation of aldrin, two of whom had abnormalities suggestive of aldrin intoxication.

\section{Case Report}

Subject 1.-A previously fit 23-year-old man experienced, whilst at work, two convulsive attacks with loss of consciousness, the attacks being separated by a two-day interval. On each occasion a work-mate noticed that the patient's limbs were twitching and that he bit his tongue. After the second attack he felt nauseated and vomited. 
He had not felt unwell and had no aura or other warning before he fell unconscious. There was no past or family history of epilepsy and no history of head injury or previous illness. On examination the tendon reflexes were found to be very brisk, but no other abnormality was elicited.

Occupational History.-He had been working with aldrin for little more than a week before his first covulsion. His job was to mix aldrin with fullers' earth, an inert filler, to make the final formulation. In order to do this, he had to transport, on a trolley, paper bags containing $56 \mathrm{lb}$. of an equal mixture of aldrin and fullers' earth, open the bags and then empty them by hand into a mechanical mixer together with more fullers' earth. He had to lean over into the exhaust hood of the mixer to do this. The firm were engaged at the time on a large export order, so that he worked a 12-hour shift every day until his first fit, handling in this way up to 12 tons of the equal mixture of aldrin and fullers' earth a day. He wore overalls for the job and a cotton wool pad as a mask, which he changed for every mix, but there was much dust on his skin and in his hair at the end of the day.

Investigations. - A radiograph of the chest and examination of the blood and urine showed no abnormality. A fat biopsy performed 15 days after his last exposure contained 60 parts per million (p.p.m.; or $6 \mathrm{mg}$. per $100 \mathrm{~g}$.) of H.E.O.D.; aldrin itself is not normally detectable in the body. In the first electroencephalogram (E.E.G.) performed one month after his last exposure to aldrin (Figure) the alpha rhythm was irregular at 10 cycles per second (c/s), voltage was low and distribution symmetrical, and there was a blocking response to visual attention. Fairly frequent complexes containing sharp and slow components, often irregular, were seen interrupting alpha activity, predominantly on the right and mainly in the temporo-occipital regions, where they often showed phase reversal. Overbreathing produced an increase of abnormality; photic stimulation evoked a following response but no other change.
Progress.-The patient had no complaints and suffered no further convulsions. He changed his job and was not exposed again to aldrin after his second fit. Subsequent examinations showed no abnormal physical signs. Further fat biopsies were not performed, but the blood H.E.O.D. level was estimated four months after the last exposure and found to be $0 \cdot 1$ p.p.m. This level had fallen to 0.05 p.p.m. five months later. Four further E.E.G.'s showed a gradual return to a normal regular alpha rhythm without interruption by discharges. In the records taken two to three months after exposure, some alpha irregularity and localized discharges persisted, and two types of more generalized discharge had appeared, mainly with drowsiness. These were (1) generalized bilaterally synchronous rhythmic theta discharges at $6 \mathrm{c} / \mathrm{s}$, the waves usually preceded by spikes to form complexes, and (2) frequent spontaneous $\mathbf{K}$ complexes which were often prolonged into more localized complexes on the right side. Four months after exposure all abnormalities had decreased, and 10 months after exposure the record both in the wakeful and drowsy state was normal.

\section{Clinical Survey}

The process involving exposure to aldrin was as follows. The aldrin concentrate was removed from tins, where it was present as a sticky, flaky mass, and ground in a mortar mill with fullers' earth to make a mixture of approximately equal parts. This rough mixture was then fed through a hopper into a micronizer, a machine for making a homogeneous mixture of small particle size by means of jets of compressed air. From the micronizer, the mixture was passed once more through a hopper, to fill 56-lb. bags. This mixture of equal parts was then further mixed with various inert fillers, such as china or local clay or fullers' earth, to make the final products containing from $1 \frac{1}{4} \%$ to $20 \%$ aldrin. The micronizer was enclosed, but exposure to the
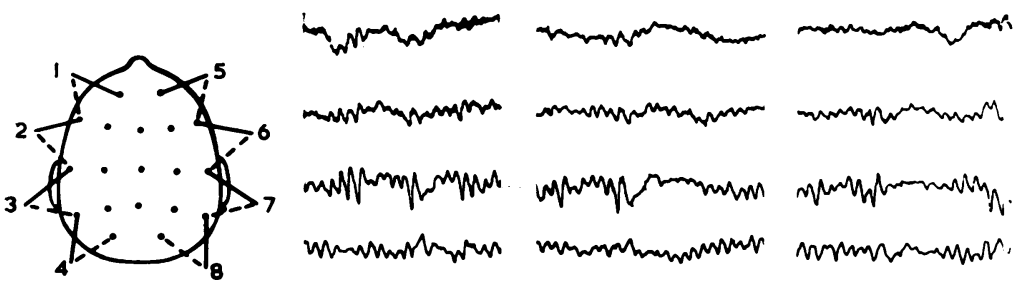

unatumbing

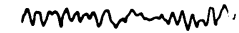
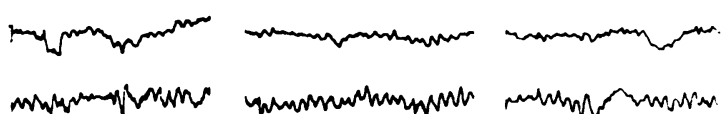

muknemprons

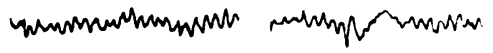

min'mplun

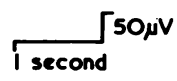

manumeners

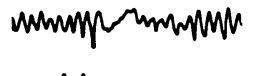

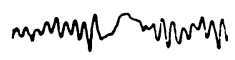

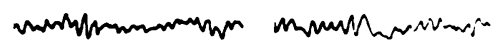

FigurE-E.E.G. from subject 1 one month after convulsive attacks. The three strips are taken from a single 20-minute recording. 
TABLE

SUMMARY OF CLINICAL AND LABORATORY FINDINGS IN 10 MEN EXPOSED TO ALDRIN

\begin{tabular}{|c|c|c|c|c|c|c|c|}
\hline \multirow{2}{*}{ Subject } & \multirow{2}{*}{ Age } & \multirow{2}{*}{ Job } & \multirow{2}{*}{ Symptoms } & \multicolumn{2}{|c|}{ E.E.G. Abnormalities } & \multicolumn{2}{|c|}{ Blood H.E.O.D. Level (p.p.m.) } \\
\hline & & & & Initial & Final & Initial & Final \\
\hline $\begin{array}{r}1 \\
2 \\
3 \\
4 \\
5 \\
6 \\
7 \\
8 \\
9 \\
10\end{array}$ & $\begin{array}{l}23 \\
49 \\
28 \\
38 \\
48 \\
31 \\
23 \\
27 \\
31 \\
41\end{array}$ & $\begin{array}{l}\text { Mixing } \\
\text { Handling concentrate } \\
\text { Handling concentrate } \\
\text { Handling concentrate } \\
\text { Mixing } \\
\text { Mixing } \\
\text { Mixing } \\
\text { Bagging and loading } \\
\text { Laboratory } \\
\text { Laboratory }\end{array}$ & $\begin{array}{l}++ \\
+ \\
+ \\
+ \\
0 \\
0 \\
0 \\
0 \\
0 \\
0\end{array}$ & $\begin{array}{l}++ \\
++ \\
+ \\
+ \\
0 \\
0 \\
0 \\
0 \\
0 \\
(+)\end{array}$ & $\begin{array}{l}0 \\
+ \\
0 \\
+ \\
= \\
= \\
\overline{-} \\
(+)\end{array}$ & $\begin{array}{l}0 \cdot 10 \\
0 \cdot 28 \\
0 \cdot 13 \\
0.04 \\
0 \cdot 08 \\
0 \cdot 05 \\
0 \cdot 12 \\
0.03 \\
0.006 \\
0.02\end{array}$ & $\begin{array}{l}0.05 \\
0.009 \\
0.016 \\
0.012 \\
= \\
= \\
= \\
\overline{-} \\
0.011\end{array}$ \\
\hline
\end{tabular}

dust occurred while the hopper was being filled and again during the filling of the bags.

After the discovery of the worker described, nine of the patient's fellow workers were examined clinically, E.E.G.s were recorded, and blood samples were taken for the estimation of H.E.O.D. content; those who showed an abnormality were seen on a second occasion three months later. Three of these nine men (see Table) had handled the almost pure aldrin concentrate and had worked with the micronizer. Another three men (see Table) were engaged in weighing the $50 \%$ aldrin and mixing it with the inert fillers in a mechanical mixer to make the final formulations. Subject 1 , the presenting patient, also belonged to this group; subject 8 (his brother) was engaged in bagging the final product and loading the bags onto lorries. The remaining two men worked in an analytical laboratory and were only exposed to aldrin in the process of making production control tests on the final products.

The clinical findings were as follows:

Subject 2 aged 49 had been with the firm for 21 years as a process worker on all types of seed dressing. For the last three years he had been in charge of the micronizing plant handling D.D.T., benzene hexachloride, dieldrin, and aldrin. For a period of three months since the start of the export order he had been working with aldrin 12 hours daily for seven days a week. This order had been completed one month before he was first seen.

During the period that he was working on the special order, he had noticed an involuntary jerking of the hands and forearms. This had been experienced most mornings and consisted of a single sudden rapid flexion movement, which caused him to drop his cup of tea on more than one occasion. During this period he had complained of irritability and insomnia. He had also suffered from vomiting without any preceding nausea soon after reaching work in the morning on a number of occasions. He had not had any headache or other symptoms. No clinical abnormality was found on examination one month after heavy exposure had ceased, but the level of H.E.O.D. in the blood was 0.28 p.p.m. The E.E.G. showed alpha irregularity with both occasional localized, and more frequent generalized, discharges of irregular slow and sharp waves, which were of greater voltage on the left side. After three months, during which time he had no further exposure, the E.E.G. showed marked improvement, but one or two localized and generalized discharges were seen with drowsiness and on overbreathing. The blood H.E.O.D. level had fallen to 0.009 p.p.m. by this time.

Subject 3 aged 28 had been employed by the firm for five months, during which time he had been working on the micronizer with subject 2 . For three months he had worked on the export order the same long hours as subject 2. On questioning, he described jerking of the arms and legs, causing him to drop a cup of tea on two occasions. On another occasion his arms and legs involuntarily came off a motor cycle and sidecar combination while he was riding. He described and reproduced a sudden rapid flexion movement involving the upper, and on the latter occasion, the lower limbs, unassociated with any change in the level of consciousness. He had also experienced a sudden jerking forward of the head while working. He complained of frequent throbbing headaches and irritability. He commented that the least thing upset him, so much so that his wife had developed the habit of putting the children to bed before he came home in the evenings. The smell of aldrin gave him nausea, and he sometimes vomited. During this time he had developed an irritating rash on the wrists, axillae, groins, genitalia, and behind the knees. He had associated the symptoms with his work, the involuntary movements having been known amongst the men as 'the works jerks'. He had taken three days' sick leave because of his symptoms. On examination one month after exposure had ceased, he was found to have very brisk tendon reflexes and bilateral patellar clonus. The blood H.E.O.D. level was 0.13 p.p.m. The initial E.E.G. showed frequent interruption of alpha rhythm by sharp and slow wave complexes, mainly localized to the right temporo-occipital region. After three months, during which time he had no further exposure, these were only seen following three minutes' overbreathing. At that time he was well, neurological examination was normal, and the H.E.O.D. level in the blood had fallen to 0.016 p.p.m. 
Subject 4 aged 38 had been working on the micronizer for a period of one year. He also started on the export order with subjects 2 and 3 , but after two months he was away from work for five weeks as a result of a hand injury and so had received less exposure than the other two men. He had not experienced involuntary movements at any time but suffered from nausea and had vomited several times while at work. A diagnosis of acute nephritis had been made eight years previously, and he had subsequently been seen at intervals at his local hospital because of persistent proteinuria. On examination, abnormal neurological signs were not found. The blood pressure was $140 / 100 \mathrm{~mm}$. $\mathrm{Hg}$, and he had mild proteinuria. The level of H.E.O.D. in the blood six weeks after the last exposure was 0.04 p.p.m. The E.E.G. showed paroxysmal discharges of mixed theta, delta, and sharp waves with phase reversal in the left fronto-temporal region where a few localized atypical spike and wave discharges occurred. Three months later, and with no further exposure, there was a slight improvement, but it was felt that either some permanent damage had occurred or, more probably, that another lesion might be present. The H.E.O.D. level in the blood had fallen to 0.012 p.p.m.

Subjects 5 to 7, who had been engaged on the mixing of the $50 \%$ aldrin mixture with the various inert fillers to make the final formulation, and subject 8 , who had been bagging and loading, had no symptoms, abnormal signs, or E.E.G. abnormalities. Their blood H.E.O.D. levels are shown in the Table. Subject 9, who worked in the laboratory, showed no abnormality. Subject 10 , the works chemist, gave a history of two severe head injuries 15 and 12 years previously, after the second of which he had been unconscious for 24 hours. He had no abnormal symptoms or signs on examination. His blood H.E.O.D. level was 0.02 p.p.m. when first seen and 0.011 p.p.m. two months later. The E.E.G. showed a localized theta abnormality in the left fronto-temporal region, which corresponded with the localization of his more severe head injury. This abnormality remained unchanged over a two-month observation period.

\section{Discussion}

In the case described by Spiotta (1951) from the U.S.A., repeated convulsions occurred after the ingestion of a quantity of aldrin with suicidal intent. In addition, there was transient albuminuria and haematuria. No abnormal neurological signs were found, but the E.E.G. showed a generalized cerebral dysrhythmia which was present for five months subsequently. Nelson (1953), also from the U.S.A., reported convulsions in three men in a group of 30 workers who had been exposed to $25 \%$ aldrin concentrate in a formulating plant. Other complaints were of nausea, vomiting, vertigo, loss of weight, malaise, and headache. A convulsive attack in a worker in Australia engaged in packing aldrin was described by Bell (1960). Analysis of a biopsy sample of fat showed the presence of 40 p.p.m. dieldrin 14 days later, and transient E.E.G. abnormalities were present which cleared within three months. Hoogendam, Versteeg, and de Vlieger (1962) reported from Holland 14 cases with convulsions over a five-year period in a plant engaged on the manufacture of aldrin. The convulsions were in three cases preceded by myoclonic jerks resulting in the catapulting of a teacup or knife out of the hand or of a sudden 'shooting away' of a leg. In other cases the convulsions occurred without prodromal symptoms or other forewarning. Specific E.E.G. abnormalities were described in all these cases; less gross changes were seen in the records of other workers who were exposed but who were without clinical involvement. The abnormalities disappeared spontaneously in almost all cases some time after cessation of exposure.

A greater number of cases of poisoning have been reported after exposure to dieldrin, the insecticide closely related to aldrin. Hayes (1957), reviewing these reports, concluded that between 10 and $20 \%$ of spraymen using dieldrin in certain malaria eradication campaigns at that time had evidence of intoxication; half of them had suffered epileptiform convulsions. In milder cases symptoms complained of were headache, blurred vision, dizziness, nausea, malaise, insomnia, and slight involuntary movements. In more severe cases involuntary movements were more pronounced, sometimes causing the patient to fall without loss of consciousness, and in other cases convulsions occurred with loss of consciousness.

In the present series the convulsive attacks with loss of consciousness experienced by subject 1 and the myoclonic jerks and other symptoms described by subjects 2 and 3 are characteristic of the clinical picture of aldrin poisoning. The symptoms were transient and were related to exposure to the insecticide. The H.E.O.D. content of body fat of 60 p.p.m. in subject 1 was higher than that reported previously in exposed workers. This figure is 300 times higher than the mean H.E.O.D. content of body fat from 131 necropsies from non-industrially exposed subjects in Southern England reported by Hunter, Robinson, and Richardson (1963). Their mean figure was 0.21 p.p.m., only two of their samples containing more than 1.0 p.p.m.; the highest value was 1.29 p.p.m. The same investigators also performed the estimations of H.E.O.D. concentration in the present series, using the gas-liquid chromatographic method, so that the results can be considered directly comparable. There is no doubt therefore that subject 1 had received a heavy exposure to aldrin in a short time. It would have 
been interesting to know the H.E.O.D. content of body fat in the other two men with symptoms, but it was not felt justifiable to subject these men, who had only mild involvement, to a surgical procedure requiring the removal of $5 \mathrm{~g}$. of fat for chemical analysis.

The necessity of performing a fat biopsy for the laboratory confirmation of aldrin or dieldrin poisoning could be obviated if an accurate method were available for the determination of small quantities of H.E.O.D. in the blood and if this could be shown to be representative of the whole body burden. Using the gas-liquid chromatographic method, Robinson (1963) found a measurable quantity of H.E.O.D. in blood samples from 12 non-industrially exposed control subjects, ranging from 0.0005 p.p.m. to 0.004 p.p.m., with a mean value of 0.0012 p.p.m., and presented his evidence of identification of this small quantity. Experimental results obtained from dosing rats with aldrin and dieldrin gave evidence of a dynamic equilibrium between the H.E.O.D. concentration in blood and that in other organs (Robinson, 1963), so that it is not unlikely that the concentration of H.E.O.D. in blood is in fact an index of the body burden in people with essentially stable body weight and repeated exposure to aldrin or dieldrin. These small quantities of H.E.O.D. found in body fat and blood samples from the nonindustrially exposed population are almost certainly related to the ingestion of foodstuffs containing trace quantities of the insecticides aldrin and dieldrin.

Unfortunately, the initial blood sample from subject 1 had been lost in transit, but on a subsequent examination, four months after his last exposure to aldrin, the level of H.E.O.D. in the blood was 0.1 p.p.m., or 84 times the mean H.E.O.D. concentration in the blood of the non-exposed subjects. The two men who had suffered myoclonic jerks had blood H.E.O.D. levels of 0.28 p.p.m. and 0.13 p.p.m. one month after the last exposure. The only other value above $0 \cdot 1$ p.p.m. was found in subject 7 , who had neither clinical nor E.E.G. abnormality, but whose blood sample was taken two weeks after his last exposure. Owing to the unavoidable time interval which had elapsed between the presence of symptoms and the taking of the blood samples, it is not possible to comment on the level of blood H.E.O.D. which might be related to the development of symptoms other than to say that this level is likely to be above 0.1 p.p.m. The figures given in this investigation can only be regarded as evidence of increased absorption of aldrin. This was found in nine of the 10 men investigated.

As regards the electroencephalographic findings, Spiotta (1951) and Hoogendam et al. (1962) have shown abnormalities in cases of aldrin toxicity of a type that they associate with brain stem injury. All their patients who had suffered convulsions were described as having $3 \mathrm{c} / \mathrm{s}$ spike and wave or multiple spike and wave discharges whereas less seriously affected patients showed bilaterally synchronous theta discharges. In our series, although the basic abnormality in all patients is of a type associated with epilepsy, the nature of the discharges has tended to be somewhat different. Generalized $3 \mathrm{c} / \mathrm{s}$ spike and wave discharges were not seen, and only in the two most severely affected patients were generalized discharges seen at all, these being associated with localized cortical discharges. However, only one man had had generalized convulsions, and, as previously mentioned, there was some delay between exposure and examination, so it is possible that changes previously reported might have been missed. In the moderately intoxicated men, localized disturbance of cortical activity was seen alone and consisted of either localized spike and wave discharges or frequent interruption of the alpha rhythm by sharp waves followed by a slow wave, or transient suppression of the alpha rhythm. The abnormalities all gradually decreased or disappeared with clinical improvement over periods of four to 10 months after cessation of exposure except in two men, one of whom had a history of severe head injuries and had no signs of aldrin toxicity; the other was probably mildly affected but in addition had a seven-year history of nephritis but no clinically detectable lesion of the central nervous system. It was thus considered that in this small group of 10 men, as in some cases illustrated previously by Nelson (1953), there was in three evidence of transient cortical damage in that localized or focal spike and wave discharges occurred, either alone or in addition to the generalized bisynchronous discharges which were more suspicious of subcortical disturbance. We agree with Hoogendam et al. (1962) that the E.E.G. is a useful method of monitoring workers who are likely to be exposed to excessive amounts of aldrin.

It should be stressed that in a case of epilepsy of late onset poisoning by one of these chlorinated hydrocarbon insecticides should be considered in the differential diagnosis of the condition where there is a history of occupational or other unusual exposure.

\footnotetext{
We are grateful to Dr. C. G. Hunter, D.S.C., and Dr. J. Robinson, of the Tunstall Laboratory, Sittingbourne, Kent, for performing the analysis of the fat and blood samples for H.E.O.D. We would like to thank Dr. S. C. Last for his help with the E.E.G.s. We would also like to thank the factory management for making the examination of the workers seen in the survey possible.
} 


\section{REFERENCES}

Bann, J. M., DeCino, T. J., Earle, N. W., and Sun, Y. P. (1956). J. agr. Food Chem., 4, 937.

Bell, A. (1960). Med. J. Aust., 2, 698.

Hayes, W. J. (1957). Puhl. Hith Rep. (Wash), 72, 1087.

Hoogendam, I., Versteeg, J. P. J., and de Vlieger, M. (1962). Arch. environm Hlth, $4,86$.

Hunter, C. G., Robinson, J., and Richardson, A. (1963). Brit. med. J., 1,221 .

Nelson, E. (1953). Rocky Mtn med. J., 50, 483.

Robinson, J. (1963). Third International Meeting in Forensic Immunology, Medicine, Pathology and Toxicology, London.

Spiotta, E. J. (1951). Arch. industr. Hyg., 4, 560.

Winteringham, F.P.W., and Barnes, J. M. (1955). Physi.l. Rev., 35 , 701 .

\section{Addendum}

Recently, two further episodes of aldrin intoxication have occurred at the same factory. Subject 2 in the series, whilst again exposed to aldrin concentrate in circumstances similar to those described above, experienced three attacks of loss of consciousness on one day and two attacks on a subsequent day. The concentration of H.E.O.D. in the blood (which had fallen to 0.009 p.p.m. between periods of exposure) was 0.53 p.p.m., and the H.E.O.D. content of body fat was at the unprecedented level of 149 p.p.m. three weeks after the last exposure. Another worker at the factory, who had not been exposed to aldrin on the previous occasion, also lost consciousness and convulsed whilst at work handling the $50 \%$ aldrin mixture. The concentration of H.E.O.D. in the blood was 0.13 p.p.m. and in body fat 44 p.p.m. after a five-week time interval. The E.E.G. showed abnormalities similar to those already described. Both men were admitted to hospital, and we are grateful to Dr. David Kendall, consultant neurologist, for allowing us to see his patients. 